\title{
POR QUE A FRATERNIDADE É UMA CATEGORIA POLÍTICA DO E NO CONSTITUCIONALISMO CONTEMPORÂNEO BRASILEIRO?
}

WHY FRATERNITY IS A POLITICAL CATEGORY OF AND IN BRAZILIAN CONTEMPORARY CONSTITUTIONALISM?

"A utopia, então, não é tanto uma fuga da realidade, mas, sim, a tentativa de evocar com a escrita uma realidade melhor,

graças à força do pensamento e da palavra".

(Domenico de Masi)

\section{Paulo de Tarso Brandão ${ }^{1}$}

Maurizio Oliviero²

\section{IIdete Regina Vale da Silva ${ }^{3}$}

1 Doutor em Direito pela Universidade Federal de Santa Catarina, Procurador de Justiça do Ministério Público do Estado de Santa Catarina, Professor do Programa de Pós-graduação Stricto Sensu em Ciência Jurídica da Universidade do Vale do Itajaí - UNIVALI em seus cursos de Doutorado e Mestrado em Ciência Jurídica.

2 Doutor em Direito Comparado e Catedrático da Universidade de Perugia - Itália. Professor Titular das disciplinas de Direito Comparado e Direito Islâmico. Professor visitante com bolsa CAPES no Programa de Pós-Graduação Stricto Sensu em Ciência Jurídica - Cursos de Mestrado e Doutorado, professor visitante e pesquisador em diversas universidades (Columbia University, Al-Quds de Jerusalém e Heildelberg, Alemanha - Max Planck Institut e Universidade de Alicante na Espanha. Embaixador do Programa Erasmus por Itália. (oliviero@unipg.it).

3 Doutora em Ciência Jurídica pela Universidade do Vale do Itajaí - UNIVALI (2014) e mestre pelo mesmo Programa de Pós-graduação Stricto Sensu em Ciência Jurídica da UNIVALI, 
Resumo: A adjetivação fraterna conferida à sociedade no texto do Preâmbulo da Constituição Brasileira de 1988 tem uma chave de leitura: a fraternidade articulada em equivalência política com a liberdade e a igualdade - síntese do universalismo moderno - seria um Princípio do Universalismo Político e, consequentemente, uma Categoria Política. A fraternidade, entendida como uma Categoria Política do e no Constitucionalismo Contemporâneo, contém um referencial teórico e prático que permite tornar a construção de uma Sociedade Fraterna critério de decisão adequada à Constituição Brasileira de 1988.

Palavras-chave: Estado Constitucional. Constitucionalismo Contemporâneo. Preâmbulo. Fraternidade.

Abstract: The adjective fraternal, given to the Society in the text of the Preamble to the 1988 Brazilian Constitution, has a key to the reading: Fraternity articulated as a political equivalent to freedom and equality - synthesis of modern universalism would be a Principle of Political Universalism and hence a Political Category. Fraternity, understood as a Political Category of and in Contemporary Constitutionalism contains a theoretical and practical framework that helps make the construction of a Fraternal Society a decision-making criterion that is appropriate to the 1988 Brazilian Constitution.

Keywords: Constitutional State. Contemporary constitutionalism. Preamble. Fraternity.

Riassunto: L'aggettivazione fraterna conferita alla società nel Preambolo della Costituzione Brasiliana del 1988 ha una chiave di lettura: la fraternità articolata in equivalenza politica con libertà e uguaglianza - sintesi dell'universalismo moderno sarebbe un Principio dell'Universalismo Politico e, di conseguenza, una Categoria Politica. La fraternità, intesa come Categoria Politica del e nel Costituzionalismo Contemporaneo, contiene un riferimento teorico e pratico che permette far sì che la costruzione di una Società Fraterna diventi un criterio di decisione adeguato alla Costituzione Brasiliana del 1988. 
Parola chiave: Stato Costituzionale. Costituzionalismo Contemporaneo. Preambolo. Fraternità.

\section{INTRODUÇÃO}

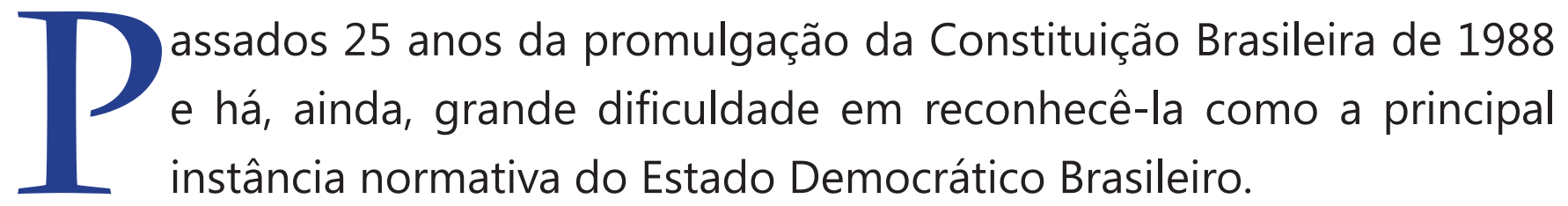

Encontra-se no texto do Preâmbulo da Constituição Brasileira de 1988 uma chave de leitura: a adjetivação Fraterna, conferida à Sociedade Brasileira.

O Preâmbulo da Constituição Brasileira de 1988 diz que a Sociedade Fraterna é a Sociedade a ser construída. Daí, a necessidade de desenvolver o estudo da Fraternidade.

A Fraternidade é um Princípio do Universalismo Político e, consequentemente, uma Categoria Política, representando um referencial teórico e prático ainda inédito e que não pode e não deve ser desprezado pelo Constitucionalismo Contemporâneo.

\section{CONSIDERAÇÕES INICIAIS}

O Brasil é considerado um país de reconhecida modernidade tardia, porque não implementou o Estado Social. A promulgação da Constituição Brasileira de 1988, instituindo um Estado Democrático, veio, justamente, para buscar suprir essa defasagem.

É certo que a Constituição Brasileira de 1988 é um plano de desenvolvimento do projeto da modernidade, logo, é preciso fazer com que o Estado Democrático Itajaí/SC. (2009). Bolsista da CAPES pelo Programa de Doutorado Sanduiche no Exterior - PSDE, no período de 01.04 a 31.07.2012. Especialista em Direito do Trabalho e, atualmente, presta serviços de consultoria jurídica trabalhista na Empresa Irmãos Fischer S/A. Indústria e Comércio em Brusque/SC (ildetervs@gmail.com). 
instituído - e esse, juntamente, com o Direito - seja colocado a serviço da Sociedade, construindo-a, sem regredir nunca no nível cultural adquirido.

No entanto, no Brasil, a matriz teórica da Análise Econômica do Direito4, que tem fundamentado o discurso público e submetido o Direito a uma racionalidade do econômico, traz ranhuras à democracia e faz com que a Constituição Brasileira de 1988 não seja "levada a sério como limite e documento"5.

Constitucionalmente, os neoliberais conseguiram "substituir a histórica relação causa-efeito - que desde os gregos antigos se apresentava como parâmetro epistêmico -, pela ação eficiente, confundindo, não por acaso, efetividade (que visa aos fins), com eficiência (que está atrelada a meios)" ${ }^{\prime 6}$.

Sem maiores embaraços, a eficiência, atada aos parâmetros neoliberais da concorrência, produtividade e competividade e com aparência de ética universal e apresentada "como se fosse a única alternativa para a resolução dos problemas, é inserida no imaginário social pela falácia desenvolvimentista que, desde a modernidade, tem por base uma racionalidade dominadora, excludente e que encobre a diferença, a alteridade"7.

O principal disfarce do discurso neoliberal é o do desenvolvimento econômico: "naturalizado como sendo uma das exigências decorrentes da globalização, sem qualquer possibilidade de discussão"8. As questões sociais são despolitizadas pelo discurso político hegemônico, que indica "um caminho natural mercadológico da coisa. O antagonismo social é revelado em nome dos interesses da comunidade inserida na ordem mundial. A eficiência faz com que as ideias que 'funcionam'

4 A Análise Econômica do Direito é a denominação de um movimento metodológico que surge nos anos de 1960 - do século passado - na Universidade de Chicago e que "busca aplicar os modelos e teorias da Ciência Econômica na interpretação e aplicação do Direito". Ronald Coase, Richard A. Posner e Guido Calabresi, sendo os dois primeiros professores da Universidade de Chicago e o último, professor da Universidade de Yale, são os ilustres precursores do movimento. ROSA, Alexandre Morais da; LINHARES, José Manuel Aroso. Diálogos com a Law and Economics. p. 19.

5 ROSA, Alexandre Morais da; LINHARES, José Manuel Aroso. Diálogos com a Law and Economics. p. 16

6 MARCELINO JR., Julio Cesar. Princípio Constitucional da Eficiência Administrativa: (des)encontros entre economia e direito. Florianópolis: Habitus Editora, 2009. p. 185.

7 MARCELINO JR., Julio Cesar. Princípio Constitucional da Eficiência Administrativa: (des)encontros entre economia e direito. p. 188-189.

8 ROSA, Alexandre Morais da; LINHARES, José Manuel Aroso. Diálogos com a Law and Economics. p. 24-25. 
sejam aplicadas irrefletidamente, sem demoras." ${ }^{19}$

A Constituição Brasileira de 1988 está "à deriva do discurso neoliberal"10 "é, preciso, de uma vez por todas, discutir e cambiar, pois, o critério", porque o que existe no Brasil, é um deficit social e este é o motivo pelo qual as instituições da Modernidade devem ser defendidas do neoliberalimo pós-moderno ${ }^{11}$. A interferência do paradigma neoliberal traz dificuldades para reconhecer a Constituição como a principal instância normativa do Estado Constitucional Brasileiro

\section{CONSTITUCIONALISMO CONTEMPORÂNEO E ESTADO CONSTITUCIONAL BRASILEIRO}

O constitucionalismo pressupõe a existência de uma Constituição escrita e rígida, que contém um Tribunal Constitucional capaz de fazer valer os direitos fundamentais nela reconhecidos ${ }^{12}$. Adefiniçãojurídica do termo constitucionalismo significa "um complexo de instituições e de princípios que, essencialmente, teoriza a separação de poderes e a garantia dos Direitos Fundamentais do homem em contraposição ao absolutismo de outrora". ${ }^{13}$

Constitucionalismo Contemporâneo é a expressão que Streck propõe para romper com o positivismo jurídico, em contraposição ao neoconstitucionalismo ${ }^{14}$. No período que segue a Segunda Guerra Mundial, o Constitucionalismo Contemporâneo se ergue em "contraposição ao neoconstitucionalismo, compreendido como um movimento que privilegiou a atuação de juízes e tribunais

9 ROSA, Alexandre Morais da. A Constituição no país do jeitinho: 20 anos à deriva do discurso neoliberal (Law and Economics). In: Revista do Instituto de Hermenêutica Jurídica. Vol. 1 (6), Porto Alegre, 2008. p. 21.

10 ROSA, Alexandre Morais da. A Constituição no país do jeitinho: 20 anos à deriva do discurso neoliberal (Law and Economics). In: Revista do Instituto de Hermenêutica Jurídica. Vol. 1 (6), Porto Alegre, 2008. p. 15 e 34.

11 STRECK, Lênio Luiz. BOLZAN DE MORAIS, José Luis. Ciência Política \& Teoria do Estado. p. 84.

12 MATTEUCCI, Nicola. El Estado Moderno. Lexico y Exploraciones. Trad. Juan Marcos de Lafuente. Madrid: Uniòn Editorial, 2010. p. 173.

13 OLIVIERO, Maurizio. STAFFEN, Márcio Ricardo. Narcisismo Constitucional: Considerações sobre o Constitucionalismo Árabe a partir da Hermenêutica Filosófica. Revista NEJ - Eletrônica. Vol. 16 - n. 3 - p. 268-280 / set-dez 2011. p. 270.

14 STRECK, Lenio Luiz. Compreender o Direito. Desvelando obviedades do discurso jurídico. São Paulo: Editora Revista dos Tribunais, 2013. p. 20. 
reconhecendo-Ihes poderes discricionários, repristinando as teses positivistas"15 em virtude da nova forma de interpretar.

O Constitucionalismo Contemporâneo chegou ao Brasil nos anos 90 do século $X X$, estabelecendo um novo paradigma e/ou proporcionando novos fundamentos para introduzir uma nova forma de interpretar e aplicar o Direito. Em tempos de intersubjetividade, é possível verificar que, no Brasil, o Constitucionalismo Contemporâneo "não consegue superar a vigência dos Códigos - ainda que esses, em grande parte, de validade constitucional duvidosa - e, a resistência de significativa parcela de juristas, que continuam trabalhando com modelos liberais-individualistas" 16 .

No Brasil, além de prevalecer as velhas formas de interpretar e aplicar o Direito, aposta-se ainda no protagonismo judicial como forma de concretizar direitos fundamentais ${ }^{17}$. Os efeitos dessa aposta se contrapõem ao plano de desenvolvimento do projeto da modernidade, considerando que o judiciário brasileiro é formado, em grande maioria, por "juízes, advogados e promotores absolutamente 'colonizados' e 'seduzidos' pelo discurso econômico que possui como meta o desmantelamento estatal"18, em detrimento do plano que há na Constituição Brasileira de 1988 para o desenvolvimento do projeto da modernidade.

A destinação do Estado Democrático instituído pela Assembleia Nacional Constituinte é assegurar direitos sociais e individuais como a liberdade, a segurança, o bem-estar, o desenvolvimento, a igualdade e a justiça, considerados valores supremos de uma Sociedade Fraterna, pluralista e sem preconceitos. Esse plano de desenvolvimento do projeto da modernidade, traçado no Preâmbulo da Constituição Brasileira de 1988, pode ser percebido por meio de uma simples leitura do texto da Constituição, que é marcado:

15 STRECK, Lenio Luiz. Compreender o Direito. Desvelando obviedades do discurso jurídico. p. 20.

16 STRECK, Lenio Luiz. Compreender o Direito. Desvelando obviedades do discurso jurídico. p. 20.

17 STRECK, Lenio Luiz. O que é isso - decido conforme minha consciência? Porto Alegre: Livraria do Advogado, 2010. p. 17.

18 MARCELINO JR., Julio Cesar. Princípio Constitucional da Eficiência Administrativa: (des)encontros entre economia e direito. p. 185. 
[...] pelo conjunto de seus princípios, por sua carta de direitos fundamentais, pela fórmula do Estado (Democrático de Direito) com a centralidade assumida por sua finalidade transformadora das circunstâncias históricas de exclusão e desigualdade social que caracterizam a história brasileira, seja durante o período monárquico, seja na fase republicana ${ }^{19}$.

O êxito desse modelo de Estado Constitucional está no caminho que se deve percorrer, ou seja, a democratização de mãos dadas com as melhorias das condições de vida e de renda da população. ${ }^{20}$ Encontra-se, então, na tipologia dos Estados Constitucionais entendidos como resultado e prestação dos processos culturais - que vão passando de geração para geração e são sempre retomados como patrimônio cultural ${ }^{-21}$, essa perspectiva que, para o desenvolvimento do projeto da modernidade no Brasil, deve ter a pretensão de não regredir nunca no nível cultural adquirido, mantendo-o e, se possível, melhorá-lo22.

O Estado Constitucional Brasileiro, entendido como progresso cultural, revelase uma ideia otimista e um desafio para o futuro que permite compreender a Constituição Brasileira de 1988 como Projeto Cultural. A Constituição Brasileira de 1988, entendida como Projeto Cultural, deve ser a expressão da condição do desenvolvimento cultural do povo brasileiro, servindo de instrumento à autoapresentação cultural, de espelho do seu patrimônio cultural e o fundamento da sua esperança ${ }^{23}$, da sua relocalização identitária. Consoante, é possível propor entender a Constituição Brasileira como um Projeto Cultural, uma proposta que serve compreender a Constituição Brasileira de 1988 com a principal instância normativa do Estado Constitucional Brasileiro.

Logo, a Constituição Brasileira de 1988 como Projeto Cultural é entendida como

19 BOLZAN DE MORAIS, José Luis; ESPINDOLA, Ângela Araújo da Silveira. O Estado e seus limites: reflexões em torno dos 20 anos da Constituição brasileira de 1988. In: Revista do Instituto de Hermenêutica Jurídica. Vol. 1 (6) Porto Alegre: 2008. p. 213.

20 OLIVIERO, Maurizio. STAFFEN, Márcio Ricardo. Narcisismo Constitucional: Considerações sobre o Constitucionalismo Árabe a partir da Hermenêutica Filosófica. Revista NEJ - Eletrônica, Vol. 16 - n. 3 - p. 268-280 / set-dez 2011. p.273.

21 HÄBERLE, Peter. Per una Dottrina della Costituzione come Scienza della Cultura. p.32.

22 HÄBERLE, Peter. Per una Dottrina della Costituzione come Scienza della Cultura. p. 32. HÄBERLE, Peter. El Estado Constitucional. Trad. Hector Fix-Fierro. México: Universidad Nacional Autônoma de México, 2003. p. 02.

23 HÄBERLE, Peter. Per una Dottrina della Costituzione come Scienza della Cultura. p. 32-33. 
produto $^{24}$ de um processo ${ }^{25}$ de transformação cultural do Estado Constitucional Brasileiro e, simultaneamente, um processo de construção da Sociedade Brasileira que é: uma Sociedade Fraterna, pluralista e sem preconceitos, uma perspectiva de discussão que pode e deve servir para cambiar o critério.

\section{O PAPEL DO PREÂMBULO NA FORMAÇÃO DA CULTURA CONSTITUCIONAL BRASILEIRA}

Entender o Estado Constitucional Brasileiro como progresso cultural e, portanto, uma aquisição cultural, conjuntamente com a ideia inicial de que Estado e Direito, devem estar a serviço da Sociedade ${ }^{26}$ e constitui as primeiras premissas para compreender a Constituição Brasileira de 1988 como Projeto Cultural e, consequentemente, formar uma Cultura Constitucional.

Cultura Constitucional é definida por Häberle como a expressão adequada a tudo aquilo que atende à forma não estritamente jurídica da Constituição de uma comunidade política. ${ }^{27}$.

Na formação de uma Cultura Constitucional, o Preâmbulo é um elemento que oferece, ao direito constitucional, um campo de trabalho muito importante ${ }^{28}$. A análise dos preâmbulos, segundo Häberle, dá bons resultados às Constituições entendidas

(...) como ordenamento jurídico fundamental do Estado e sociedade, constituição como processo público, como orientação para a contínua renovação dos pactos de tolerância entre os cidadãos, como legitimação, limitação e racionalização do poder tanto político quanto social e como expressão do estado de desenvolvimento cultural de um povo ${ }^{29}$.

24 Produto - A etimologia da palavra produto tem origem no latim "productus, a, um, levado para diante, alogado, desenvolvido [...]". HOUAISS, Antônio; VILLAR, Mauro de Salles. Dicionário Houaiss da língua portuguesa. Rio de Janeiro: Objetiva, 2009. p.1556.

25 Processo - A etimologia da palavra processo tem origem no latim "processus, us' ação de adiantar-se, movimento para adiante, andamento". HOUAISS, Antônio; VILLAR, Mauro de Salles. Dicionário Houaiss da língua portuguesa. p. 1555.

26 BRANDÃO, Paulo de Tarso. Vinte anos de Constituição, é hora de fazê-la valer. In: Revista do Instituto de Hermenêutica Jurídica. p. 367.

27 HÄBERLE, Peter. Per una Dottrina della Costituzione come Scienza della Cultura. p. 38

28 HÄBERLE, Peter. Per una Dottrina della Costituzione come Scienza della Cultura. p. 92-93.

29 [...]: costituzione come ordinamento giuridico fondamentale di Stato e società, costituzione come processo pubblico, come cornice per il continuo rinnovo dei parti di tolleranza tra i cit- 
Os textos dos preâmbulos contêm fórmulas de compromisso e hamonização elaboradas pelos constituintes do Estado Constitucional para transmitir, mais ou menos conscientemente, uma linguagem justa para sintonizar o texto constitucional positivo sinalizado pela via da cultura ${ }^{30}$. Os conteúdos culturais conferem aos preâmbulos uma validade mais profunda e uma capacidade vinculativa muito maior do que admite a interpretação tradicional do jurista constitucionalista ${ }^{31}$.

Os preâmbulos surgem como uma tentativa de manter a Constituição no tempo de reger a hereditariedade cultural e futuro cultural, a tradição e o progresso. Essas grandes dimensões correspondem também a uma linguagem de maior alcance. O constituinte se insere, deste modo, no contexto histórico mais amplo e não se concebe como um autônomo a esse respeito, explica Häberle. Do ponto de vista teórico e formal, o reconhecimento dessa obrigação pode ser considerado como uma forma de vinculação e obrigação para si e por si: na sua essência e na prática, trata-se de uma relação fiduciária sem a qual não seria possível produzir a Constituição concreta. ${ }^{32}$

Os preâmbulos podem conter uma visão geral do contexto histórico e cultural da Constituição, fazendo com que seja, sempre, a quintessenza do contexto da Constituição que, reconhecido como componente do texto constitucional, é, enfim, possível obter um conteúdo legal diferenciável com precisão. ${ }^{33}$

Nessa perspectiva, encontra-se no Preâmbulo da Constituição Brasileira de 1988 um elemento da Cultura Constitucional e seu texto é a expressão da ideia para a qual o Estado Constitucional Brasileiro foi instituído e, logicamente, os termos dessa

tadini, come legittimazione, limitazione e razionalizzazione del potere tanto político quanto sociale e come espressione dello stato di sviluppo culturale di un popolo. Questa concezione della costituzione, basata sul diritto e sulle scienze della cultura, dà buona prova specialmente nell'analisi dei preamboli. HÄBERLE, Peter. Per una Dottrina della Costituzione come Scienza della Cultura. p. 93.

30 HÄBERLE, Peter. Per una Dottrina della Costituzione come Scienza della Cultura. p. 92.

31 HÄBERLE, Peter. Per una Dottrina della Costituzione come Scienza della Cultura. p. 92.

32 HÄBERLE, Peter. Per una Dottrina della Costituzione come Scienza della Cultura. p. 94

33 HÄBERLE, Peter. Per una Dottrina della Costituzione come Scienza della Cultura. p. 94 
ideia devem ser conhecidos e comunicados àqueles a quem o Estado Constitucional Brasileiro é destinado, inicialmente, a servir, ou seja, a Sociedade Brasileira.

A fórmula prescrita no texto do Preâmbulo da Constituição Brasileira de 1988 comunica ao povo Brasileiro a destinação do Estado Constitucional instituído, que é e deve ser a construção de uma Sociedade Fraterna, pluralista e sem preconceitos:

Nós, representantes do povo brasileiro, reunidos em Assembleia Nacional Constituinte para instituir um Estado Democrático, destinado a assegurar o exercício dos direitos sociais e individuais, a liberdade, a segurança, o bem-estar, o desenvolvimento, a igualdade e a justiça como valores supremos de uma sociedade Fraterna, pluralista e sem preconceitos, fundada na harmonia social e comprometida, na ordem interna e internacional, com a solução pacífica das controvérsias, promulgamos, sob a proteção de Deus, a seguinte CONSTITUIÇÃO DA REPÚBLICA FEDERATIVA DO BRASIL.

O Estado Constitucional é instituído e anunciado ao mesmo tempo em que se torna anunciador de uma Sociedade Fraterna, pluralista e sem preconceitos, sendo esta que é, e deve ser, a Sociedade Brasileira. Logo, a Sociedade Fraterna é o tipo de Sociedade Brasileira a ser construída.

Contemporaneamente, as categorias pluralistas e sem preconceitos podem ser facilmente relacionadas à Sociedade e compreendidas no contexto constitucional e político. Inobstante, o mesmo não ocorre com a palavra Fraterna, que confere qualificação e identificação à Sociedade Brasileira. Para construir uma Sociedade Fraterna, o estudo da Fraternidade se apresenta como exigência e demanda à organização da ordem social e convivência política no Estado Democrático Brasileiro e na formação de uma Cultura Constitucional.

\section{FRATERNIDADE: PRINCÍPIO FUNDAMENTAL E FUNDANTE DA E NA CONSTITUIÇÃO BRASILEIRA DE 1988}

O Preâmbulo da Constituição Brasileira de 1988 diz que a Sociedade Fraterna é a Sociedade a ser construída, daí a ideia da Fraternidade ser um princípio fundante 
da Constituição Brasileira e princípio fundamental tal como é a liberdade e da igualdade.

Reporta-se à ideia da Fraternidade que, juntamente, com a liberdade e a igualdade, constituíram a síntese política e cultural do universalismo político. A relação de interdependência entre os três princípios constitui "um precedente teórico de notável relevância" ${ }^{\prime 34}$ e um fundamento teórico ainda inédito à Humanidade, justificado na constatação de que os princípios da liberdade e da igualdade - que muitas vezes competiram entre si - são incompletos ou ainda não atingiram toda a sua potencialidade. ${ }^{35}$ Não obstante, a Fraternidade permaneceu esquecida, "inédita e irresolvida em relação aos outros temas da igualdade e da liberdade"36.

A síntese do universalismo Moderno - Liberdade, Igualdade, Fraternidade ${ }^{37}$ oculta uma realidade de consequências enigmáticas e paradoxais que precisam ser esclarecidas ${ }^{38}$. A compreensão da tríade como um precedente teórico de notável relevância perpassa, necessariamente, pelo fato de a Fraternidade ter sido esquecida, pelo menos teoricamente, no cenário político do mundo ocidental. Raramente se encontra um verbete específico à Fraternidade nos dicionários políticos. O fato da doutrina política não ter incorporado a nova condição que a Fraternidade ascendeu na Modernidade, pode ser verificada nas diversas disciplinas que têm a Política como objeto de estudo, nas quais a ideia de Fraternidade não aparece nos ensinamentos consolidados ${ }^{39}$. A ausência da

34 BAGGIO, Antonio Maria. Fraternidade e reflexão politóloga contemporânea. In: Princípio Esquecido/2: Exigências, recursos e definições da Fraternidade na política. Trad. Durval Cordas, Luciano Menezes Reis. Vargem Grande Paulista, SP: Cidade Nova, 2009. p. 09.

35 BAGGIO. Antonio Maria. Il Dibatteto intorno all'idea di Fraternità: prospettive di ricerca politologica. http://www.cittanuova.it/FILE/PDF/articolo20813.pdf. Acesso em 08 de setembro de 2010.

36 RESTA, Eligio. Direito Fraterno. p. 09.

37 Há alguns aspectos nos fatos históricos revelando que, os três princípios comumente referenciados como lema da Revolução Francesa não são a sua causa, mas as consequências que dela decorrem, formando uma "fenomenal síntese cultural e política". Baggio pondera que, embora não se possa atribuir à Revolução Francesa a paternidade histórica da tríade, pode-se reconhecer que, somente a partir desse evento histórico, a liberdade e a igualdade se tornam "princípios constitutivos da ordem pública e se impõem". BAGGIO, Antonio Maria. Fraternidade e reflexão politológica contemporânea. In: Princípio Esquecido/2: Exigências, recursos e definições da Fraternidade na política. p. 10.

38 MARRAMAO, Giacomo. Passaggio a Occidente. Filosofia e globalizzazione. p. 186.

39 BAGGIO, Antonio Maria. Fraternidade e reflexão politológica contemporânea. In: BAGGIO, Antonio Maria. (Org.). O Princípio Esquecido/2: Exigências, recursos e definições da Fraternidade na política. p. 09. 
Fraternidade nos dicionários políticos é uma falha que não se justifica, além de uma lacuna que não deve ser desprezada ${ }^{40}$. Bobbio diz que é uma "lacuna não sem influência, visto que se trata de um dos princípios chaves do tríptico"41. Logo, convém apostar na Fraternidade ${ }^{42}$.

No Brasil, convém apostar na ideia de Fraternidade como princípio fundante e princípio fundamental da e na Constituição Brasileira de 1988, no desenvolvimento do projeto da modernidade.

A ideia da Fraternidade traz um precedente teórico de grande valor e, ainda, inédito, possível de se reportar na atualidade, porque permite pensar a igualdade e a diversidade humana a partir dos Estados Constitucionais, sem pretender alcançar o espírito universalista de uma Cultura, muito ao contrário.

As lições deixadas pela história devem ser aprendidas, cuidando para não incorrer nos erros já experimentados nos últimos dois séculos. A recuperação e a valorização da Fraternidade - o Princípio Esquecido - em sua dimensão Política deve fazer brotar uma relação entre os três princípios que, juntos, devem constituir um fundamento garantidor do sentido pleno que a Política pretendeu construir por meio da história ${ }^{43}$.

\section{FRATERNIDADE COMO CATEGORIA POLÍTICA}

A Fraternidade na condição de Princípio do Universalismo Político é uma palavra estratégica para expressar uma ideia capaz de compor uma Categoria ${ }^{44}$ Política e que deve ser (re)construída, na atualidade, buscando, não só compensar todo esse tempo de ausência na teoria e na prática da Política, mas de criar critérios de decisão adequada à Constituição Brasileira de 1988.

40 Raramente capita di trovare una specifica voce a essa dedicata nei lessici politici: non a caso (per limitarci al lessico contemporaneo degli italiani) una tale voce non è rinvenibile neppure nell'edizione aggiornata del Dizionario di politica (1983) di Noberto Bobbio, Nicola Matteuci e Gianfranco Paquino. Lacuna non ininfluente, visto che si tratta di uno dei principi-chiave del $<<$ trittico $>>$. MARRAMAO, Giacomo. Passaggio a Occidente. Filosofia e globalizzazione. p.186.

41 [...] del Dizionario di politica (1983) di Noberto Bobbio, Nicola Matteuci e Gianfranco Paquino. Lacuna non ininfluente, visto che si tratta di uno dei principi-chiave del $<<$ trittico $\rangle>$. MARRAMAO, Giacomo. Passaggio a Occidente. Filosofia e globalizzazione. p. 186.

42 RESTA, Eligio. Direito Fraterno. p.136.

43 BAGGIO, Antonio Maria. La Fraternità: uma nuova categoria nello spazio pubblico. p. 12.

44 PASOLD, Cesar Luiz. Metodologia da Pesquisa Jurídica: teoria e Prática. p. 25. 
Marramao recorda que a definição aristotélica do homem como animal racional (zóon lógon échon - antecedida pelos pré-socráticos e pela sofística maior) tem, já a partir de Sócrates, a concepção de uma importante ideia no sentido de compreender uma nova forma de prática e busca incessante do saber por via dialógica, recebendo o nome de filosofia atribuída à polis, espaço próprio do homem ${ }^{45}$. Para Marramao, essas são premissas que darão pleno sentido à célebre definição aristotélica do homem como zóon politikón, como animal naturaliter político; quem vive fora da polis é uma besta ou um Deus ${ }^{46}$.

A palavra Política deriva de polis. Polis, segundo Mateucci, é o resultado de um lento e espontâneo desenvolvimento da convivência civil na história social e política grega ${ }^{47}$. Historicamente, desde a época da polis, a palavra Política sofreu muitas transformações, modificando em muito o seu conceito ${ }^{48}$ e dando origem a distintos significados, tanto na linguagem comum como na linguagem científica ${ }^{49}$. Mateucci afirma que, atualmente, nos países democráticos, há uma grande nostalgia pela Política que já não existe, uma Política que dá sentido à existência ${ }^{50}$.

Na concepção de Bobbio ${ }^{51}$, Política é uma expressão de estudo das atividades que têm relação com o Estado, buscando, mais especificamente, verificar as possibilidades de cumprimento da finalidade última do Estado, que deve estar a serviço da Sociedade para a qual ele se destina ${ }^{52}$.

Os sinais de que a Política não tem mais o sentido da existência são percebidos nas limitações que os princípios da liberdade e da igualdade têm sofrido nesses Estados. A manifestação desses sinais ocorre por meio de duas 45 MARRAMAO, Giacomo. La passione del presente. Breve lessico della modernità-mondo. p.157-158.

46 ARISTÓTEleS. Política. Trad. Pedro Constantin Tolens. São Paulo: Martin Claret, 2007. Título Original: Politikón.

47 MATTEUCCI, Nicola. EI Estado Moderno. Lexico y Exploraciones. p. 315.

48 MATTEUCCI, Nicola. EI Estado Moderno. Lexico y Exploraciones. p.328-329.

49 MATTEUCCI, Nicola. EI Estado Moderno. Lexico y Exploraciones. p. 337.

50 MATTEUCCI, Nicola. EI Estado Moderno. Lexico y Exploraciones. p. 339.

51 BOBBIO, Norberto. Verbete "Ciência Política". In: BOBBIO, Norberto et al. Dicionário de

Política. Trad. Carmem C. Varrialle. et al. 4. ed. Brasília: Editora Universidade de Brasília, 1992. v. 2, p. 954.

52 BRANDÃO, Paulo de Tarso; SILVA, Ildete Regina Vale da. A Fraternidade como uma categoria (da) política. In: Revista Diálogos Críticos. Seção Ciências Jurídicas. Vol 2 (1) Maranhão, 2012. p. 03. 
tipologias, segundo Baggio: externa e interna. A externa se refere "às relações entre as regiões geopolíticas e econômicas em que o Planeta se divide" ${ }^{25}$, entre os muitos exemplos possíveis, está o fato de não se aplicar os indicadores do não desenvolvimento apenas aos países não desenvolvidos, mas também aos mais fortemente industrializados ${ }^{54}$. Um sinal paradoxal e, ao mesmo tempo, significativo da tipologia externa, está nas relações entre os hemisférios norte e sul sobre os quais, por muitas décadas, era comum pensar

[...] que esses conceitos correspondiam a delimitações geográficas precisas; hoje, no entanto, existem Terceiro Mundo e um Quarto dentro do Primeiro e do Segundo, não compostos por imigrantes recentes e pobres, mas produzidos pela própria incerteza do sistema, ou seja, pela fragilidade que continua a acompanhar a realização dos princípios da liberdade e da igualdade ${ }^{55}$.

A tipologia interna é, segundo Baggio, aquela que ocorre justamente nas Sociedades mais industrializadas, na qual há uma tendência em acreditar que a liberdade e a igualdade foram concretizadas em virtude da produção de bens materiais e culturais, em quantidade maior que as necessidades da população. De maneira inesperada, contudo, "essas sociedades continuam permeadas de amplas faixas de pobreza" 56 .

Diante desse cenário global, insinua-se a renúncia dos grandes Princípios do Universalismo Político, justificando que esses seriam impossíveis de serem realizados nas Sociedades amplas e complexas. Baggio observa que, em alguns casos, busca-se manter a satisfação imediata com aquilo que parece ser mais fácil, desistindo, simplesmente, de lutar para manter um horizonte ideal de pensamento ${ }^{57}$. Em outros casos, "os princípios universais são modificados, modulados de maneira diferente, quase como se houvesse um desejo de mudar a perspectiva da cultura política sem, entretanto, dar um aviso explícito dessa intenção" 58 .

53 BAGGIO, Antonio Maria. Fraternidade e reflexão politológica contemporânea. p. 11. 54 BAGGIO, Antonio Maria. Fraternidade e reflexão politológica contemporânea. p. 11-12. 55 BAGGIO, Antonio Maria. Fraternidade e reflexão politológica contemporânea. p. 11-12. 56 BAGGIO, Antonio Maria. Fraternidade e reflexão politológica contemporânea. p. 12. 57 BAGGIO, Antonio Maria. Fraternidade e reflexão politológica contemporânea. p. 13. 58 BAGGIO, Antonio Maria. Fraternidade e reflexão politológica contemporânea. p. 13. 
Éjustamente no processo de substituição de tríades, que muitos aspectos deveriam ser analisados, diz Baggio, chamando a atenção para um aspecto, especialmente: "a passagem de uma tríade a outra corresponde à passagem de uma concepção da vida e da pessoa a outra" ${ }^{59}$. Em outras palavras, explica que a percepção do conceito de Pessoa é modificada quando se deixa de valorizar a dimensão política para valorizar apenas a dimensão privada, ou seja, tudo fica reduzido àquilo que é pessoal. Nesse sentido, voltar a atenção à tríade tradicional tem o significado de "libertar-se", de dar uma guinada, de abertura a um projeto de transformação ${ }^{60}$ social, pela organização da Sociedade - (re)pensando-a - e pela convivência política.

Evidencia-se que (re)propor a tríade é (re)propor a Fraternidade como Princípio do Universalismo Político e, portanto, como Categoria (da) Política. Nessa perspectiva, a Fraternidade tem uma relação de interdependência com a liberdade e a igualdade. A relação de interdependência entre os três princípios é uma relação dinâmica e de significados inéditos e, ainda, inexplorados. No momento em que a relação de uma com a outra é considerada, cada uma delas alcança o seu próprio significado e a Fraternidade alcança a sua essencial forma de politização nessa relação ${ }^{61}$.

Na história da Humanidade, a ausência da Fraternidade como Princípio do Universalismo Político resultou na falta do êxito pretendido com a liberdade e a igualdade, despertando um sentimento de ineficácia das ações políticas, acompanhada de uma debilidade do pensamento. Percepção essa que não resulta apenas na falta dos conhecimentos individuais em específico, explica Baggio, mas na falta de um método com o qual se desenvolve o pensar e o agir político ${ }^{62}$. O resultado da aplicação separada e contraposta desses dois princípios produziu sistemas sociais e econômicos que só parcialmente poderiam reproduzir as suas intenções, simplesmente porque são expressões parciais de humanismo e, em não poucos casos, os ideais de liberdade e igualdade ligados ao poder resultaram em ações contrárias do que aquelas que inicialmente haviam sido propostas ${ }^{63}$.

59 BAGGIO, Antonio Maria. Fraternidade e reflexão politológica contemporânea. p. 15. 60 BAGGIO, Antonio Maria. Fraternidade e reflexão politológica contemporânea. p. 15.

61 BAGGIO, Antonio Maria. La Fraternità: uma nuova categoria nello spazio pubblico. p. 09.

62 BAGGIO, Antonio Maria. La Fraternità: uma nuova categoria nello spazio pubblico. p. 10.

63 BAGGIO, Antonio Maria. La Fraternità: uma nuova categoria nello spazio pubblico. p. 11. 
A Fraternidade como Categoria Política significa dizer que, por meio dela, será possível "formar juízos políticos em número ilimitado, porém, tomando uma natureza precisamente determinada: formando tais juízos se produz pensamento político, através da ótica da Fraternidade"64.

Fraterno é relativo ou pertencente a irmão, Fraternal, do vocábulo fraternu em uma declinação de fraternus. Nos dicionários de língua portuguesa a palavra Fraternidade - fraternitas, fraternitatis e fraternitate - é o substantivo feminino que denota a ideia de: "(a) laço de parentesco de irmãos; irmandade; (b) união, afeto de irmão para irmão; (c) o amor ao próximo; fraternização; (d) a harmonia e união entre aqueles que vivem em proximidade ou que lutam pela mesma causa etc. ${ }^{65 ",}$ relacionados a: (a) unir(-se) como irmãos; confraternizar(-se); (b) travar amizade íntima; confraternizar; (c) associar-se (a outrem); irmanar-se; e, (d) comungar as mesmas ideias ou convicções de; harmonizar-se, confraternizar-se ${ }^{66}$.

A adjetivação que a palavra Fraterna concede e projeta à Sociedade Brasileira no texto do Preâmbulo da Constituição Brasileira de 1988 dá a ela uma condição de verbete com acepção constitucional e política ainda inexplorada no Constitucionalismo Contemporâneo Brasileiro, requerendo, assim, uma melhor compreensão do sentido que essa ideia compõe, além de dar origem a um referencial teórico e prático com condição para restituir à Política o sentido da existência. E, nessa perspectiva, construir uma Sociedade Fraterna é condição para tornar o tipo de Sociedade que se quer construir, critério de decisão adequada à Constituição Brasileira de 1988.

\section{CONSIDERAÇÕES FINAIS}

Com relação à pergunta elaborada como título desse artigo: Por que a Fraternidade é Categoria Política do e no Constitucionalismo Contemporâneo Brasileiro? Responde-se que: A Fraternidade é uma Categoria Política do e no 64 BAGGIO, Antonio Maria. La Fraternidad como Categoría Política. In: PIETRO, Antonio Márquez (Coord.). Fraternidad y Justicia. Granada: Editorial Comares. 2012. p. 07.

65 HOUAISS, Antônio; VILLAR, Mauro de Salles. Dicionário Houaiss da língua portuguesa. p. 927.

66 HOUAISS, Antônio; VILLAR, Mauro de Salles. Dicionário Houaiss da língua portuguesa. p. 927. 
Constitucionalismo Contemporâneo Brasileiro, porque há, no texto do Preâmbulo da Constituição Brasileira de 1988, de forma precisa e convencionada, a expressão da ideia para a qual o Estado Constitucional Brasileiro é instituído e destinado a servir a Sociedade Brasileira.

OPreâmbuloentendidocomoumelementoquecompõeaCulturaConstitucional, além de dar uma visão geral do contexto histórico e cultural da Constituição, oferece, também, maior validade e capacidade vinculativa de interpretação à Constituição, conferindo, assim, legitimidade ao Estado Constitucional. O texto do Preâmbulo na Constituição Brasileira é o vetor necessário à compreensão da destinação dada ao Estado Democrático instituído.

A adjetivação Fraterna conferida à Sociedade Brasileira revela uma realidade social a ser construída: uma Sociedade Fraterna. Nessa perspectiva, o estudo da palavra Fraterna se apresenta como exigência e demanda à organização da ordem social e convivência política no Estado Democrático Brasileiro, constituindo, assim, uma Categoria Política do e no Constitucionalismo Contemporâneo.

A Fraternidade, entendida como uma Categoria Política do e no Constitucionalismo Contemporâneo, contém um referencial teórico e prático que permite tornar a construção de uma Sociedade Fraterna critério da decisão adequada à Constituição Brasileira de 1988.

\section{REFERÊNCIAS}

ARISTÓTELES. Política. Trad. Pedro Constantin Tolens. São Paulo: Martin Claret, 2007. Título Original: Politikón.

BAGGIO, Antonio Maria (Org.). O Princípio Esquecido/1. Trad. Durval Cordas, Iolanda Gaspar, José Maria de Almeida. Vargem Grande Paulista: Cidade Nova, 2008.

. (Org.). O Princípio Esquecido/2: Exigências, recursos e definições da Fraternidade na política. Trad. Durval Cordas, Luciano Menezes Reis. Vargem Grande Paulista: Cidade Nova, 2009.

La Fraternidad como Categoria Politica. In: PIETRO, Antonio Márquez (Coord.).

Fraternidad y Justicia. Granada: Editorial Comares, 2012. 
BIBLIOTECA DA PRESIDÊNCIA DA REPÚBLICA. Disponível em: http://www.biblioteca. presidencia.gov.br/ex-presidentes/jose-sarney. Acesso em 20 fevereiro 2014.

BOBBIO, Norberto et al. Dicionário de Política. Trad. Carmem C. Varrialle et al. 4. ed. Brasília: Editora Universidade de Brasília, 1992. v. 2.

BOLZAN DE MORAIS, José Luis; ESPINDOLA, Ângela Araújo da Silveira. O Estado e seus limites: reflexões em torno dos 20 anos da Constituição brasileira de 1988. In: Revista do Instituto de Hermenêutica Jurídica. Vol. 1 (6) Porto Alegre: 2008.

BRANDÃO, Paulo de Tarso. Vinte anos de Constituição, é hora de fazê-la valer. In: Revista do Instituto de Hermenêutica Jurídica. Vol 1 (6), Porto Alegre, 2008.

BRANDÃO, Paulo de Tarso; SILVA, Ildete Regina Vale da. A Fraternidade como uma categoria (da) política. In: Revista Diálogos Críticos. Seção Ciências Jurídicas. Vol 2 (1) Maranhão, 2012.

HÄBERLE, Peter. Per una Dottrina della Costituzione come Scienza della Cultura. Roma: Carocci editore. 2001.

El Estado Constitucional. Trad. Hector Fix-Fierro. México: Universidad Nacional Autônoma de México, 2003.

HOUAISS, Antônio; VILLAR, Mauro de Salles. Dicionário Houaiss da língua portuguesa. Rio de Janeiro: Objetiva, 2009.

MARCELINO JR., Julio Cesar. Princípio Constitucional da Eficiência Administrativa: (des) encontros entre economia e direito. Florianópolis: Habitus Editora, 2009.

MARRAMAO, Giacomo. La passione del presente. Breve lessico della modernità-mondo. Torino: Bollati Boringhieri, 2008.

. Passaggio a Occidente. Filosofia e globalizzazione. 2. ed. Torino: Bollati Boringhieri. 2009.

MASI, Domenico de. O Futuro chegou. Modelos de Vida para uma Sociedade Desorientada. Trad. Marcelo Costa Sievers. Rio de Janeiro: Casa da Palabra, 2014.

MATTEUCCI, Nicola. El Estado Moderno. Lexico y Exploraciones. Trad. Juan Marcos de Lafuente. Madrid: Uniòn Editorial, 2010.

OLIVIERO, Maurizio. STAFFEN, Márcio Ricardo. Narcisismo Constitucional: Considerações sobre o Constitucionalismo Árabe a partir da Hermenêutica Filosófica. Revista NEJ - Eletrônica, Vol. 16 - n. 3 - p. 268-280 / set-dez 2011. 
Metodologia da Pesquisa Jurídica: Teoria e Prática. 12. ed. rev. Florianópolis: Conceito Editorial/Millenium, 2008.

PIETRO, Antonio Márquez (Coord.). Fraternidad y Justicia. Granada: Editorial Comares, 2012.

RESTA, Eligio. Direito Fraterno. Trad. Sandra Regina Martini Vial. Santa Cruz do Sul: EDUNISC, 2004.

ROSA, Alexandre Morais da. A Constituição no país do jeitinho: 20 anos à deriva do discurso neoliberal (Law and Economics). In: Revista do Instituto de Hermenêutica Jurídica. Vol 1 (6), Porto Alegre, 2008.

; LINHARES, José Manuel Aroso. Diálogos com a Law and Economics. Rio de Janeiro: Editora Lumen Juris, 2009.

. O que é isso - decido conforme minha consciência? Porto Alegre: Livraria do Advogado, 2010.

. BOLZAN DE MORAIS, José Luis. Ciência Política \& Teoria do Estado. 7. ed. 2.tir. Porto Alegre: Livraria do Advogado, 2012.

Compreender o Direito. Desvelando obviedades do discurso jurídico. São Paulo: Editora Revista dos Tribunais, 2013. 